ISSN: 0213-2079 - ISSN electrónico: 2386-3889

DOI: https://doi.org/10.14201/shhmo202042291114

\title{
ANDANZAS Y TRIBULACIONES DE UN MERCADER DE CACAO. JUAN MARCOS JAQUETO, MERCADER VENE- CIANO MUERTO EN LA PROVINCIA DE TABASCO (1603)
}

\author{
Adventures and Tribulations of a Cocoa Merchant. Juan \\ Marcos Jaqueto, Venetian Merchant Dead in the Province \\ of Tabasco (1603)
}

Béatrice Perez

Sorbonne Université, CLEA

beatrice.perez@sorbonne-universite.fr

Fecha de recepción: 11/09/2020

Fecha de aceptación: 20/10/2020

RESUMEN: A través del estudio del itinerario de Marcos Juan Jaqueto, este artículo pretende centrarse en la vida de un comerciante de clase media en los confines de la Nueva España. La compañía mercantil de cacao del veneciano Marcos Juan Jaqueto, fallecido en Tabasco en 1603, nos informa sobre su clientela novohispana, las formas de préstamo y la forma de atesorar la riqueza acumulada. La información sobre el comercio temprano de cacao y plata a finales del siglo XVI es, por lo tanto, valiosa. Más elocuentemente, las cuentas de su empresa en el momento del inventario después de su muerte atestiguan las redes de comercio entre el Viejo Mundo y América, los circuitos económicos entre el Mediterráneo, el Atlántico y la costa del Pacífico. Por último, el testamento que se ha conservado da una idea de este cómputo final de la vida después de la muerte, en el que la salvación se descifra mediante la fundación de una capilla en Tlaxcala para la paz de su alma y la de sus difuntos.

Palabras clave: Nueva España; Tabasco; Tlaxcala; compañía; mercaderes; cacao; plata; comercio; siglo XVI y XVII. 
ABSTRACT: Through the study of the adventures of Marcos Juan Jaqueto, this article intends to focus on the life of a middle-class merchant in the confines of New Spain. The cocoa merchant company of the Venetian Marcos Juan Jaqueto, who died in Tabasco in 1603, informs us about his novohispanas clientele, the forms of loans and how to keep the accumulated wealth. The information on the early trade of cocoa and silver at the end of the 16th century is thus valuable. More eloquently, the accounts of his company at the time of the inventory after his death attest to the trading networks between the Old World and America, the economic circuits between the Mediterranean, the Atlantic and the Pacific coast. Finally, the will that has been preserved gives a glimpse of this final accounting of the afterlife, in which salvation is deciphered by the foundation of a chapel in Tlaxcala for the peace of his soul and that of his deceased.

Keywords: New Spain; Tabasco; Tlaxcala; company; merchants; cocoa; silver; trade; 16 th and 17 th century.

El trabajo presentado en este artículo es un esbozo de una reflexión más amplia que me gustaría llevar a cabo indagando nuevas fuentes del Archivo de Indias. Este volumen monográfico es, pues, la ocasión idónea para abrir pistas y reflexiones. El trabajo se articula esencialmente a partir de un documento procedente de la sección sevillana del Archivo de Indias, Bienes de Difunto (Contratación) y lleva -en los catálogos- el resumen siguiente:

Testimonio de los autos sobre los bienes de Marcos Juan Jaqueto, mercader, natural de Venecia, residente en Tabasco, donde murió con testamento. Albaceas: Francisco de Oro, vecino de Nueva Veracruz, Isabel Fernández, su mujer, y Francisco de Oleta, vecino de Chiapa.

Fundación de capellanía en Tlaxcala, su patrón Pedro Gutiérrez de Pisa, chantre de Tlaxcala ${ }^{1}$.

Es un documento bastante complejo ya que en realidad se compone de dos testamentos e inventarios: el testamento de Marcos Juan Jaqueto y el testamento del albacea Francisco de Oro, lo que dificulta la comprensión del proceso de cumplimiento de las voluntades de Marcos Juan y sobre todo, el hecho de que la muerte del albacea retrasara mucho este mismo proceso. De hecho, ni siquiera sabemos si llegaron a cumplirse sus voluntades: las cuentas del alcalde mayor de la provincia de Tabasco, Hernando de Mena precisamente de estos años no se pueden consultar

1. Archivo General de Indias [AGI], Contratación, 502, N. 11. 
a causa de un incendio ocurrido en el siglo XIX que sigue imposibilitando dicha consulta por razones de restauración y conservación de documentos. En cambio, contamos con la inmensa suerte de que por razones intrínsecas a la personalidad de Marcos Juan, el testamento así como el inventario de sus bienes y toda una serie de cartas y relaciones suyas se conservaron en el Archivo de Indias, en la sección Contratación. Es un trabajo que representa una apertura temática para mis investigaciones: por una parte, salgo en cierto modo de mi zona de confort que es la del mundo bajo andaluz para trasladarme a Nueva España (México) a principios del siglo XVII; pero al mismo tiempo, sigo indagando sobre los vínculos profundos que unieron el mundo mediterráneo (Venecia) y el mundo atlántico desde época muy temprana. En un primer tiempo, a modo de introducción, trataré de destacar la cronología del documento ordenando el caos de las diversas piezas, para entender la evolución del caso peculiar de Marcos Juan y lo que éste nos enseña.

Marcos Juan Jaqueto nace en fecha desconocida en la ciudad de Venecia donde es bautizado en la Casa de San Pedro. Por motivos que desconocemos, debió abandonar la ciudad adriática ya adulto para viajar a América, sin bien no poseemos ni su licencia para embarcar, ni tampoco dato ninguno sobre una carta de naturaleza o semejante: he consultado la sección de «Peticiones y memoriales de personas seculares de 1580-1606» y no consta que se conservara. Allí, en Nueva España, vivió durante cierto tiempo. Desconocemos su fecha de llegada, ni siquiera a la provincia, pero debió quedarse más de quince años en Nueva España, pues sabemos con certeza que llevaba por lo menos trece años viviendo en la provincia de Tabasco (o en la de Chiapas, pasando de la una a la otra) en el momento de su muerte. Fallece en casa de Juan Jiménez Tovar, a media legua del pueblo de Cunduacán, un martes 13 de agosto de 1603, si bien la documentación en varias ocasiones vacila en la fecha, confundiendo los meses de agosto y julio. La verdad es que la muerte se había de declarar ipso facto para que no quedasen encubiertos bienes del difunto que no hubiese declarado en su testamento, tal y como fue el caso del propio Marcos Juan quien declaró en varias ocasiones que no se alargaba en ubicarlos porque su esclavo sabía dónde estaban. El 16 de agosto es enterrado en el mismo pueblo de Cunduacán, «donde no había ni hay justicia ni escribano».

Ese mismo día, Francisco de Torres, capitán teniente general de la provincia de Tabasco recibe una carta informándole de dicha muerte, y acude ese mismo día, el 16 de agosto para averiguar los bienes de Marcos Juan, que según le habían informado «habían quedado sin orden» ${ }^{2}$. Este hombre es bastante odiado, violento y controvertido, lo que de hecho se deduce del temor que muchos sienten hacia él. En realidad, el 11 de julio, Marcos Juan había redactado un testamento ante el escribano de su majestad, Ambrosio Guerrero, y ante varios testigos, nombrando

2. AGI, op. cit., fol. 2 r. 
al menos a dos albaceas, Francisco de Oro y Francisco de Oleta. El caso es que Juan Jiménez Tovar, por miedo al teniente Torres y «para no incurrir en pena como vuestra merced me dijo por haber entregado los bienes de Figueroa (otro que había muerto en su casa) a los albaceas sin autoridad de la justicia», lo informó para que acudiera y mandara hacer informe y pesquisa de todos los bienes del difunto. Y Francisco de Torres, a pesar de alegar que estaba abrumado de trabajo «ocupado en el servicio de su magestad, y los caminos y puentes amenazados y caídos, se pone en camino desde oy dicho día» ${ }^{3}$. Y apenas llegó, entró en las propiedades de Marcos Juan y empezó a inventariar, y a reclamar, y a tasar, y a ocupar... Hasta que el 4 de septiembre de 1603, Francisco de Oleta, encomendero de una parcialidad de indios de Chiapas, Oleta, albacea y que se declaró, además, suegro del difunto, se presentó en la villa de Santa María de la Victoria, capital de Tabasco, ante el capitán Hernando de Mena, juez oficial de la Real Hacienda quejándose de que Francisco de Torres se había apropiado de los bienes de Marcos Juan aprovechándose de su ausencia. Pidió que se le remitieran el testamento y todos los bienes declarados, aceptando el albaceazgo y pidiendo justicia. Todo este largo proceso se desarrolla a lo largo de unos 170 folios. De este primer desencuentro quisiera destacar (de cara al desarrollo ulterior) la controvertida personalidad de Francisco de Torres, cuya brutalidad y codicia quedaron resaltadas de inmediato y denunciadas con medias palabras. Francisco de Torres actuó como señor y dueño, sin temor ni de Dios ni del rey. Y no es de extrañar, pues como bien lo subraya Carlos Moreno Amador, «[...] el escaso número de naturales en relación con otras provincias contribuyó de manera determinante, junto con la desidia de las autoridades virreinales, a que el alcalde mayor (o su lugarteniente -o cualquiera que tuviera cargo que le confiriera algún poder, como en nuestro caso-) se convirtiese en una especie de 'señor feudal', ejerciendo un control integral, en muchas ocasiones autoritario, sobre toda la población, al actuar y disponer sin ninguna cortapisa» (Moreno Amador, 2014: 2). En una carta que el obispo de Yucatán, Diego Vázquez de Mercado, escribía al rey en 1605 denunciaba la codicia de los 200 españoles instalados en la provincia de Tabasco, «toda gente de malas conciencias y olvidados de la obligación que deben a cristianos, por su proceder entre aquellos pobres [...] vejados y molestados con sus excesos por la codicia del cacao» ${ }^{4}$.

El caso de Marcos Juan resulta particularmente interesante porque el testamento, el inventario de bienes y la documentación (cartas, escrituras y libros -estos tan solo mencionados y descritos, pero no conservados en propio-) que dejó en «una petaca y en un cofre» dan muchísimas informaciones sobre las modalidades conflictivas de una justicia bajo influencia, y sobre el comercio colonial a

3. Ibid.

4. AGI, Audiencia de México, leg. 369. Citado por Humberto Ruz, 2016: 123. 
principios del siglo XVII. Quisiera presentar en este estudio tres aspectos que me parecen esenciales. En una primera parte, analizaré la compañía de Marcos Juan, sus instrumentos, su red clientelar y los circuitos mercantiles. En una segunda parte, intentaré exponer los negocios de Marcos Juan, mercader de cacao con una proyección americana bastante interesante, tal vez con una proyección pacífica más disimulada por las razones que diré adelante, y sin lugar a dudas, en fase de consolidación patrimonial a través del tráfico de la plata. Por fin, en la última parte, quisiera poner de relieve la personalidad de este veneciano, de una humanidad diáfana, a través de dos elementos: la fundación de una capilla en Tlaxcala, hecho que evidencia con otros elementos, una sensibilidad y religiosidad peculiar; el trato casi filial otorgado a su esclavo negro Manuel Tierra Bran, "pues en este lugar [de hijo] lo he tenido», a quien nombra albacea «sin que nadie ni justicia se lo impida» ${ }^{5}$ sabiendo de sobra que nunca un esclavo negro, por muy libre que fuese, habría sido reconocido en calidad de tal por alguien como el teniente general Francisco de Torres.

\section{LA COMPAÑÍA DE MARCOS JUAN JAQUETO}

\subsection{Los instrumentos de la compañia}

Como nos indica de forma bastante inequívoca la documentación conservada, Marcos Juan tenía una compañía mercantil de venta de cacao de cierto relieve. Sin embargo, antes de presentarla, he de solventar la difícil cuestión del estatuto de Marcos Juan, veneciano en Nueva España, mercader asentado y perfectamente integrado, comerciando y acumulando patrimonio en tierras de realengo, a pesar de la prohibición expresa que impedía la inmigración y asentamiento de los extranjeros en las Indias y de las órdenes de expulsión en contra de ellos. Marcos Juan ni era «vecino», ni era «residente» en Nueva España, los dos estatutos legales que suponían una presencia concertada con el Consejo de Indias. Se le califica con fórmulas imprecisas como «mercader que fue en esta provincia», "que se halla presente», y él mismo en su testamento se califica de «estante y tratante en esta provincia». En 1504, se habían promulgado las primeras prohibiciones del paso a Indias de los extranjeros, si bien en 1562 una cédula de Felipe II preconizaba que se aceptara como naturales a los extranjeros que llevaran viviendo diez años en los virreinatos y que estuvieran casados con naturales, lo que era el caso de Marcos Juan, puesto que era yerno de Francisco de Oleta. En 1595, por necesidades financieras, la administración filipina volvió a promulgar una nueva orden de expulsión de los territorios americanos, acompañándola de una cédula que reconocía que con los extranjeros que «convenían al servicio de su majestad»-en particular si fuesen

5. AGI, Contratación, 502, N. 11, fol. 29v. 
irlandeses y naturales de la península itálica (Herzog, 2014: 137-163; Poggio, 2011: 177-193)-, se pactara «una composición» (aquella tradicional invención fiscal tan impactante a partir de finales del siglo XV) que regularizara esta situación ilegal de acumulación de bienes, aunque fuera contraria a la legislación vigente. En teoría este sistema de composiciones, muy semejante al que se había iniciado con los conversos a principios del XVI, ofrecía una alternativa a la ilegalidad para aquellos mercaderes que buscasen asentarse en América (Poggio, 2011: 182), pero para algunos mercaderes como Marcos Juan, instalado, casado, integrado en la sociedad novohispana desde hacía muchísimo tiempo, la composición les perjudicaba en cuanto no era más que una tasa discriminatoria, a la diferencia del modus adoptado para con los conversos, a quienes las composiciones favorecían considerablemente. A lo largo de todo el documento se detectan muchas alusiones que atestiguan este sentimiento de inseguridad de los extranjeros en Nueva España, así como muchas precauciones para garantizar la posesión de sus bienes y ponerlos a salvo. Tanto más cuanto que Marcos Juan vivía en una zona portuaria, en teoría vetada a los extranjeros al igual que las zonas mineras.

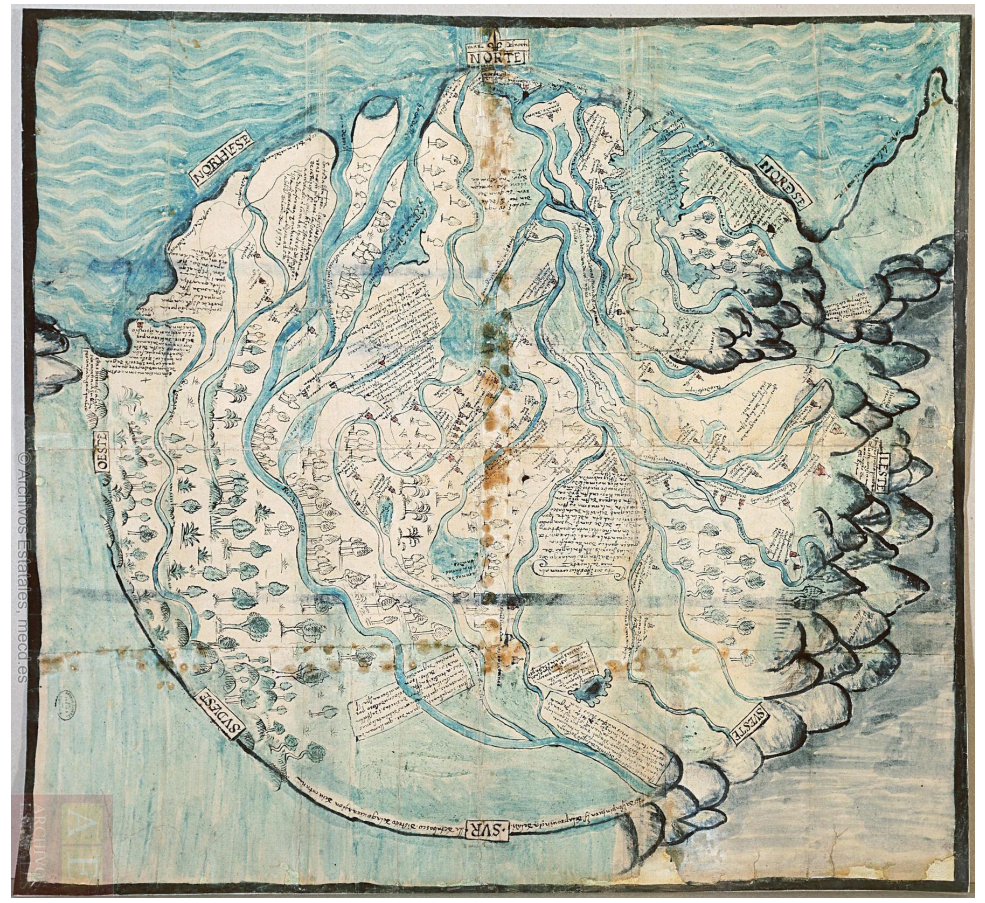

Fig. 1. Mapa de la Provincia de Tabasco, distrito de la Gobernación de Yucatán, elaborado por Melchor de Alfaro Santa Cruz en 1579, Archivo General de Indias. 


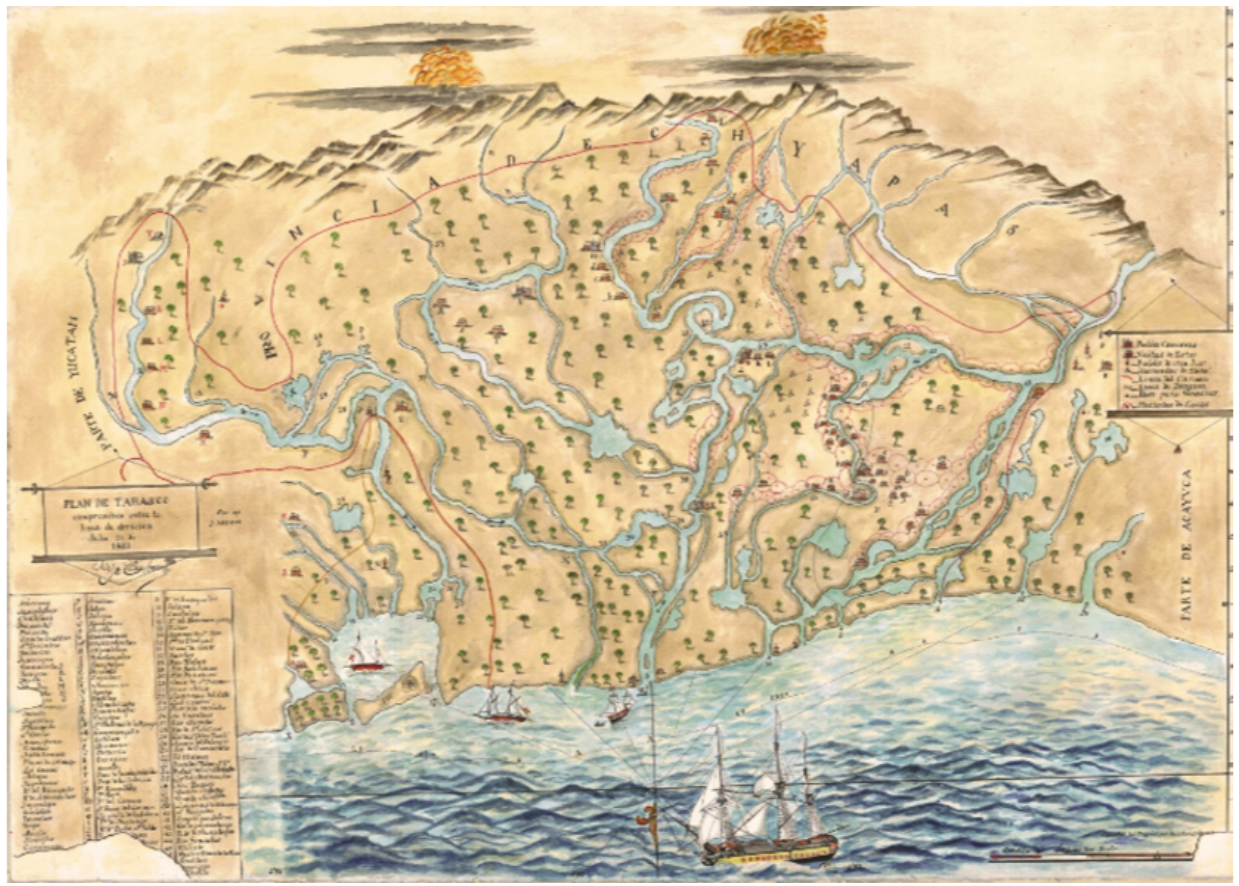

Fig. 2. $1803^{6}$, Miguel de Castro y Araoz, militar nacido en Sevilla, fue gobernador de la provincia de Tabasco de 1793 a 1810.

La provincia de Tabasco era una de las principales zonas productoras de cacao, junto con la zona de Soconusco, en Chiapas. Fue una región donde se instalaron varios mercaderes extranjeros, que convivieron con la población indígena ${ }^{7}$. Durante el periodo colonial, la provincia de Tabasco se dividía entre Chontalpa, Sierra y los Ríos (chontales, zoques y nahuas). Tal vez la instalación de Marcos Juan en Cunduacán

6. La leyenda principal figura abajo a la izquierda y señala en el mapa 52 números, que corresponden a nombres de lugares y a la riqueza hidrográfica de Tabasco (ríos, lagunas, bahías, pasos). La leyenda que está arriba a la derecha distingue los «pueblos cabeceras, visitas de estos, pueblos de otra jurisdicción, haciendas de ganado, línea del Carmen, línea de división, paso para Veracruz y haciendas de cacao». Este mapa se representó invertido, con el norte abajo y el sur arriba para representar mejor la descarga del complejo delta Grijalva-Usumacinta sobre el golfo de México.

7. En la villa de Santa María de la Victoria, en 1601, había 10 vecinos españoles, «además de 22 encomenderos, de los cuales 4 no habitaban en ella» [Moreno Amador, 2014: 20]. En 1570, se contabilizaron unos 50 vecinos españoles. Todos los especialistas concuerdan en que la gran dificultad a la hora de analizar la población española radica en la ausencia de documentación. 
fuese reciente, porque su mujer está enterrada en Ciudad Real de Chiapas. «Ricos de infinito cacao»: así calificó a los chontales el dominico fray Tomás de la Torre en 1545 cuando atravesó parte de la Chontalpa camino a Ciudad Real de Chiapas. Tabasco y Soconusco compartieron en el siglo XVI la fama de producir el cacao de mejor calidad en todo el mundo mesoamericano. El cacao servía para la bebida cotidiana, para ceremoniales, pero sobre todo como moneda (se hablaba del árbol en que crecía el dinero, y así Alfaro de Santa Cruz, uno de los autores de las Relaciones Histórico-geográficas escribía «bebían una bebida que se hace de la moneda suya, que es el cacao»). En resumidas cuentas, el cacao servía para comprarlo todo. Una cita de Gonzalo Fernández de Oviedo puede darlo a entender de forma simbólica:

Y porque en aquella tierra hay mujeres que dan por prescio sus cuerpos como entre los christianos las publicas meretrices y viven desso [...] quien las quiere para su libidinoso uso, les da por una carrera ocho o diez almendras $[\ldots]^{8}$.

El cacao empezó a ser muy demandado a raíz de los años 1580 cuando el precio se disparó, y si antes, los indios podían tributar con lo que producían, los españoles comenzaron a exigir que se les entregase el tributo en cacao. De tal modo que los autores de las Relaciones geográficas apuntan que los zoques habían intentado sembrar en la Sierra pero que se helaba el cacao (Humberto Ruz, 2016: 121-129).

Precio del cacao (Hernández Jaimes, 2008: 43-79, 54 y ss.):

$$
\begin{aligned}
& \rightarrow 1540=1 \text { carga }=6 \text { pesos } \\
& \Rightarrow 1562=1 \text { carga }=20 \text { pesos } \\
& \rightarrow 1570=1 \text { carga }=21 \text { pesos } \\
& \rightarrow 1580=1 \text { carga }=28 \text { pesos } \\
& \Rightarrow 1606=1 \text { carga }=50 \text { pesos } \\
& \rightarrow 1621=1 \text { carga }=21 \text { pesos }
\end{aligned}
$$

Fig. 3. Precio del cacao en los siglos XVI-XVII.

Sea como fuere, los instrumentos que manejaba Marcos Juan dejan intuir que la compañía practicaba todos los tipos de préstamos y ventas al por mayor y a plazo. Los inventos técnicos de finales del XV no tenían secreto ninguno para Marcos Juan, hombre de libros, cartas y cédulas. Lo primero que llama la atención es aquel «libro

8. Gonzalo Fernández de Oviedo, Historia general y natural de las Indias, t. I, lib. VIII, cap. XXX [Humberto Ruz, 2016: 116]. 
de marca mayor escrito en parte y en lo más del borrado y testado y en medio del está un golpe de cédulas y papeles» ${ }^{9}$ que más adelante se inventariaron. De hecho, según las Artes mercatoria, el mercader debía llevar tres libros: el Cuaderno (o Libro Mayor), el Giornale (o Libro Diario) y el Memoriale (o Borrador); cotejando estos libros era como hacía el balance de su actividad. Además, el mercader debía consignar diariamente un pequeño cuaderno o memorándum («tablettes de souvenance»), en el que anotará, hora tras hora, el estado de sus negocios. En el Borrador las páginas estaban numeradas para evitar que algún mercader poco escrupuloso las arrancara negando, así, una deuda, y con el mismo afán de garantía, algunos mercaderes prudentes (como era el caso de Marcos Juan, que sabía cuán vulnerable era un extranjero cuando reclamaba una deuda a un prócer de la administración colonial) solían autentificar los libros haciéndolos firmar por el co-contratante (Perez, 2016: 29 y ss). Además de este libro, Marcos Juan tenía una serie de cédulas, que en este caso eran reconocimientos de deudas, recibos, escrituras de cuantías, obligaciones, libranzas, cartas, cartas misivas, etc. El manejo de estos instrumentos de contabilidad es interesantísimo porque permite una percepción bastante inmediata de la capacidad financiera de la compañía de Marcos Juan. Por fuerza hemos de suponer que tenía un capital de cierta importancia porque vendía al fiado, a crédito, con un interés, y por ello el libro estaba «borrado y testado» [borrado cuando se terminaba de pagar la deuda, y firmado por el co-contratante para mejor autentificar la operación crediticia]. Del mismo modo, las cédulas iban «reconocidas» ${ }^{10}$ [firmadas por el co-contratante], las escrituras públicas iban con sus respectivas cartas de pago y las libranzas llevaban «a las espaldas» las cuentas ${ }^{11}$.

Por otra parte, Marcos Juan conservaba una serie de cartas, que se presentan como misivas mercantiles y cartas íntimas, entremezclando informaciones comerciales y noticias de las hermanas que se quedaron en Venecia. Así es como el mercader Jerónimo Beloni, afincado en la parroquia de San Pedro de la ciudad de Valencia, y que había sido mercader en la Nueva España, le contó a Marcos Juan, en una carta, que su hermana, Silvia Jaqueta, a quien había dejado soltera, había entrado en religión, y que tanto ella como Arcángela Jaqueta estaban vivas. La ambivalencia de las cartas acarrea una suerte de confusión entre la materia comercial expuesta -Beloni era el factor encargado de recibir en Valencia el dinero de la venta de los bienes de Marcos Juan para mandarlo a Venecia- y la confidencialidad de lo íntimo. Entre los objetos que se inventariaron, se mencionó una balanza ${ }^{12}$, la cual deja intuir que Marcos Juan cambiaba la plata, y de hecho debió ser mercader de plata y comerciarla

9. AGI, Contratación, 502, N. 11, fol. 7v.

10. AGI, Contratación, 502, N. 11, fol. 9r.

11. Ibid., fol. $8 \mathrm{v}$-fol. $10 \mathrm{r}$.

12. Ibid., fol. $8 \mathrm{r}$. 
si bien nunca lo menciona, porque como extranjero era un comercio que tenía que llevar de forma ilegal. En todo caso, la balanza parece haber sido un instrumento imprescindible de los mercaderes novohispanos a causa de un caos monetario como fue la coexistencia de pesos de oro común, de peso de plata corriente, de tostones de plata, de reales, de pesos de tipuzque -que eran de cobre- (Franklin Pease y Omar Noejovich, 2000; Stanley Burdick, 2008), que son todas las monedas que aparecen en el inventario de bienes y que hay que convertir en pesos de plata para poder cifrar el capital de la compañía. Pero antes de adentrarme en este tema, quisiera presentar la red clientelar de Marcos Juan.

\subsection{Su red clientelar}

Entre los clientes de Marcos Juan aparecen distintos grupos que describiré de forma general.

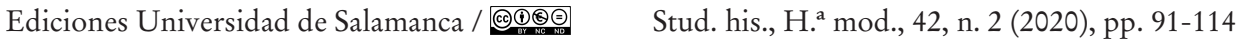


BÉATRICE PEREZ

ANDANZAS Y TRIBULACIONES DE UN MERCADER DE CACAO. JUAN MARCOS JAQUETO, MERCADER VENECIANO MUERTO EN LA PROVINCIA DE TABASCO (1603)

\begin{tabular}{|c|c|c|c|}
\hline CLIENTES & OFICIOS & RESIDENCIA & \\
\hline Alonso Gómez & & & Hermano de Juan Martín \\
\hline \multicolumn{4}{|l|}{ Álvaro Pérez } \\
\hline Ana María & Mujer de Antón García & & \\
\hline Antonio de la Luz & Maestre de barca & Tabasco & \\
\hline Balboa & & Los Ríos & \\
\hline Bartolomé Botalagata & Mercader & & \\
\hline \multicolumn{4}{|l|}{ Bartolomé Ortiz } \\
\hline Bonami de Buenami & Mercader y carcelero comentariense & México & \\
\hline Diego Bernal & Escribano público & Tabasco & \\
\hline Domingo de Ariola & Mercader tratante & Tabasco & \\
\hline \multicolumn{4}{|l|}{ Domingo Fernández } \\
\hline \multicolumn{4}{|l|}{ Felipe de Morales } \\
\hline Felipe Perales & & Tabasco & \\
\hline Francisco de Castilla & Tratante & Chiapas & \\
\hline Francisco de Oleta & $\begin{array}{l}\text { Encomendero de una parcialidad norte de Chiapas } \\
\text { (llamada Oleta, en la selva de los lacandones) }\end{array}$ & Real Ciudad de Chiapas & Suegro de Marcos Juan \\
\hline Francisco de Torres & Teniente general de la provincia de Tabasco & Santa María de la Victoria & \\
\hline Francisco Doro (de Oro) & Encomendero de San Juan de Ulúa & Nueva Veracruz & \\
\hline \multicolumn{4}{|l|}{ Francisco Gómez } \\
\hline \multicolumn{4}{|l|}{ Francisco Pérez Carrasco } \\
\hline Francisco Ruiz & Corredor & Nueva Veracruz & \\
\hline Gabriel González & & Venta de Acachapa & \\
\hline Gaspar Sánchez & Indio sastre & Jalpa & \\
\hline Gonzalo Martín & Maestre del barco San Francisco & San Juan de Ulúa & \\
\hline Hernando de Mena & Capitán, alcalde mayor de Tabasco & & \\
\hline $\begin{array}{l}\text { Isabel Hernández (mujer de } \\
\text { Francisco Doro) }\end{array}$ & & Nueva Veracruz & Mujer de Francisco Doro \\
\hline Jerónimo Beloni & Mercader que fue de la Nueva España & Valencia & \\
\hline \multicolumn{4}{|l|}{ Jorge de Valera } \\
\hline \multicolumn{4}{|l|}{ Juan Bautista de Ardalia } \\
\hline Juan Cansino & Tratante & Guatemala & \\
\hline Juan de Quintanilla & Tratante & Guatemala & \\
\hline Juan de Ribera & Teniente de Los Ríos & Los Ríos & \\
\hline Juan de Santa Ana & \begin{tabular}{|l|} 
Vaquero \\
\end{tabular} & & \\
\hline \multicolumn{4}{|l|}{ Juan Díaz de Torres } \\
\hline Juan González & Mercader portugués & Yucatán & \\
\hline Juan Jiménez Tovar & & Cunduacán & $\begin{array}{l}\text { Posee tierras cacaotales. } \\
\text { «Español y vecino desta } \\
\text { provincia» }\end{array}$ \\
\hline Juan Martín & & & $\begin{array}{l}\text { Hermano de Alonso } \\
\text { Gómez }\end{array}$ \\
\hline Juan Rodríguez & & Venta de Acachapa & \\
\hline Julian Romero & & Venta de Acachapa & \\
\hline Leonor la Mulata & & Amatitán & \\
\hline Leonor La Negra & Esclava & Amatitán & \\
\hline Manuel de Tierra Bran & Esclavo & Tabasco & \\
\hline María Pérez & & Nueva Veracruz & \\
\hline Miguel Sánchez Voz & Mercader & Ríos de Usumacinta & \\
\hline Pedro Gutiérrez de Pisa & Chantre de Tlaxcala & Tlaxcala & \\
\hline Pedro Yáñez & Piloto & & \\
\hline Periáñez Arráez & Capitán de barca & Tabasco & \\
\hline Santi Fantoni & Regidor mercader & Cádiz & \\
\hline
\end{tabular}

Fig. 4. La red clientelar de Marcos Juan Jaqueto.

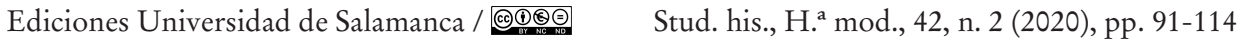


El primer núcleo lo constituían mercaderes selectos del consulado de México, como Bonami de Buenami, también mercader veneciano ${ }^{13}$, y carcelero comentariense $^{14}$; Domingo de Ariola, registrado como "comerciante vasco», presente en Tabasco en 1603, si bien pidió al Consejo de Indias licencia para viajar a Nueva España en 1606 (Heredia Herrera, 1984); mercaderes importantes de Guatemala, como Juan Cansino y Juan de Quintanilla [que eran conversos notorios, en particular Cansino, de la gran familia de los conversos sevillanos de finales del XV, quienes abandonaron el nombre Cansino a principios del XVI en Sevilla para retomarlo en América; un tal Juan Cansino de hecho estaba empadronado en 1604 en Guatemala ${ }^{15}$;; y otros mercaderes de las provincias limítrofes, como el portugués Juan González, de Yucatán; o Miguel de Sánchez Voz, de Ríos de Ucumacinta. Estos mercaderes, por su localización, nos indican el radio mercantil de la compañía de Marcos Juan.

Otro grupo lo constituían una serie de prohombres de la administración novohispana, como el propio Hernando de Mena, capitán y alcalde mayor de Tabasco; el teniente de gobernador de Tabasco para la región de los Ríos, Juan de Ribera; Francisco de Oro, encomendero de San Juan de Ulúa [su albacea]; Francisco de Oleta, su suegro y también albacea, encomendero de Oleta, en la selva chiapaneca del norte, una región bastante hostil. De hecho, esta tierra se conoce como «la tierra de los lacandones», porque éstos protagonizaron una rebelión violentísima en 1585 resistiendo ferozmente a los agentes del gobierno colonial. Se conocen algunos textos acerca de estas rebeliones en Chiapas que han sido publicados, y en particular algunas declaraciones de caudillos lancandones, como «no queremos ser cristianos», que de hecho es el título de la obra de Jan de Vos (De Vos, 1990). Francisco de Oleta intervino en la pacificación de esta rebelión y por ello se le dio a cambio una parcialidad en dicha región donde los lacandones siguieron viviendo en las zonas selváticas de difícil acceso. Es importante tenerlo en cuenta para entender mejor la historia del esclavo negro Manuel de Tierra $\operatorname{Bran}^{16}$ más adelante. Podemos afirmar

13. AGI, Contratación, 502, N. 11, fol. 20v : «Ytem, declaro por mis bienes 550 pesos que me deve Bonami de Bonami, natural de Venecia, mercader en México [...]».

14. «Carcelero comentariense» era un título prestigioso de cargo que se encomendaba a personas notables, similar al de escribano de la universidad de mercaderes, nombrado en este caso el 22 de abril de 1600. El documento está conservado en México, en el Archivo de la Nación [Mijares Ramírez, 1997]; lo que me autoriza a pensar que es probable o posible que se hayan conservado documentos sobre Marcos Juan en los archivos locales mexicanos que no he consultado.

15. AGI, Contratación, 502, N. 11, fol. 22v: «Iohan Cansino, vecino de Guatemala [...]. Ytem me deve Juan de Quintanila que dicen está en la provincia de Guatemala [...]». Jickling, 1982: 183-184.

16. AGI, Contratación, 502, N. 11, fol. 23v: «Ytem declaro que tengo por mi esclavo un negro Manuel de Tierra Bran el cual me ha servido tiempo de trece años como buen esclavo, bien y fielmente $[\ldots] »$. 
que si Marcos Juan no tenía licencia para comerciar en América, sí gozaba de un fuerte respaldo administrativo, lo que atestigua su perfecta inserción en la sociedad novohispana y su perfecto manejo de los mecanismos locales de sociabilidad.

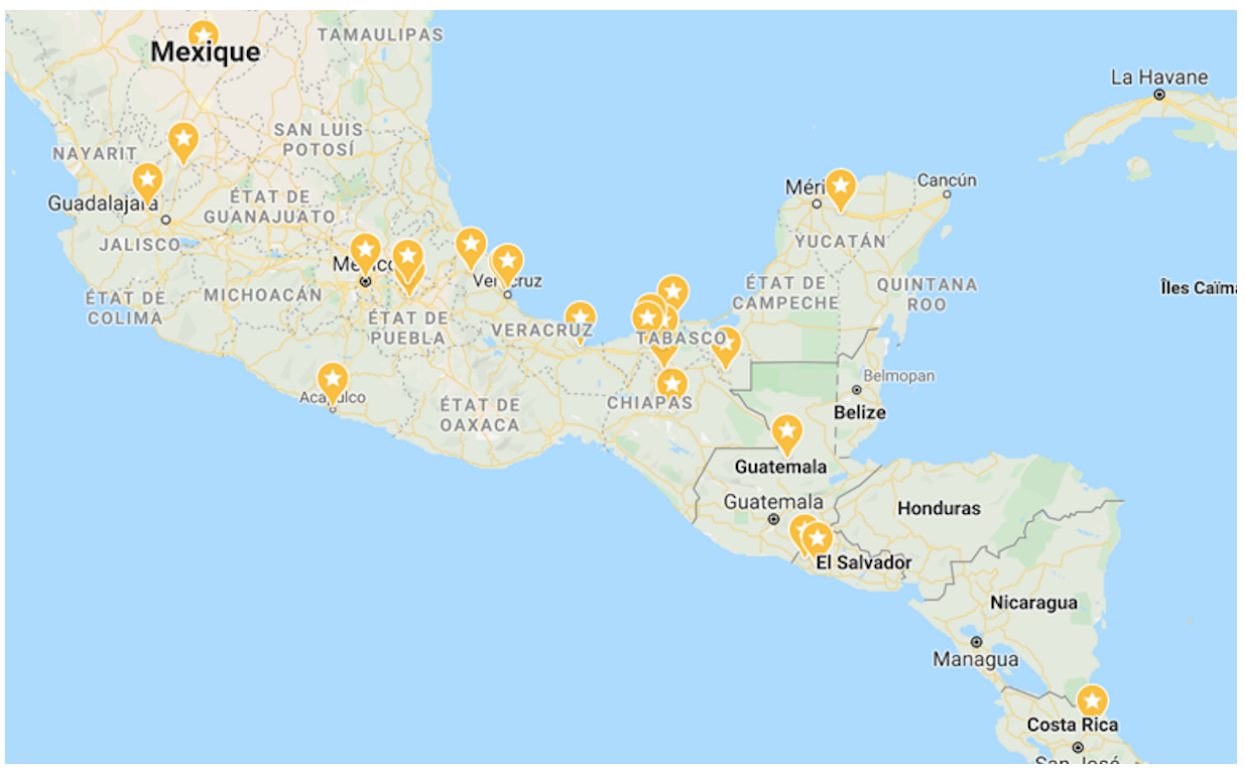

Fig. 5. Radio comercial de Marcos Juan Jaqueto.

Un tercer grupo lo formaba un elenco de pilotos y de maestres de barco: Antonio de la Luz, maestre de barca de Tabasco; Gonzalo Martín, maestre de barco de San Juan de Ulúa; y el piloto portugués, Pedro Yáñez. Este Pedro Yáñez resultaba bastante conocido en la historiografía, como «insuperable técnico a la entrada del río de la Plata a finales del XVI». De hecho, Pedro Yáñez, más conocido como Periáñez, fue quien llevó el primer barco mercante que mandara el obispo de Tucumán de Buenos Aires a Brasil (Laguarda Trías, 1988: 79-80). El hecho de que se encontrara una libranza de Pedro Yáñez entre los documentos de Marcos Juan demuestra que el radio comercial del veneciano se extendía probablemente hasta el virreinato de Perú.

El último grupo, lo componen esclavos, como la negra Leonor de Amatitán, quien vendía corales a Marcos Juan; la mulata Leonor, también de la región de Amatitán; indios productores de cacao como Gaspar Sánchez de Zacatecas; poblaciones indias, como los pueblos zacatunes de Yucatán; corredores y barqueros. En fin, emerge un mundo anónimo de intermediarios que hicieron factible la actividad económica. Tan solo a través de un hombre, Marcos Juan Jaqueto, esta red articulaba clientelas en 
las antípodas, próceres coloniales (como un tal Balboa, muy mal pagador), encomenderos, productores y esclavos, corredores y factores.

\subsection{Los circuitos mercantiles}

El mapa presentado arriba (Fig. 5) materializa la red comercial de Marcos Juan. Sin embargo, el camino señalado abajo entre Ayapa, Acachapan y Tacotalpa, reúne los diversos lugares donde este mercader conservaba algunos bienes que fue necesario inventariar a raíz de la lectura del testamento.

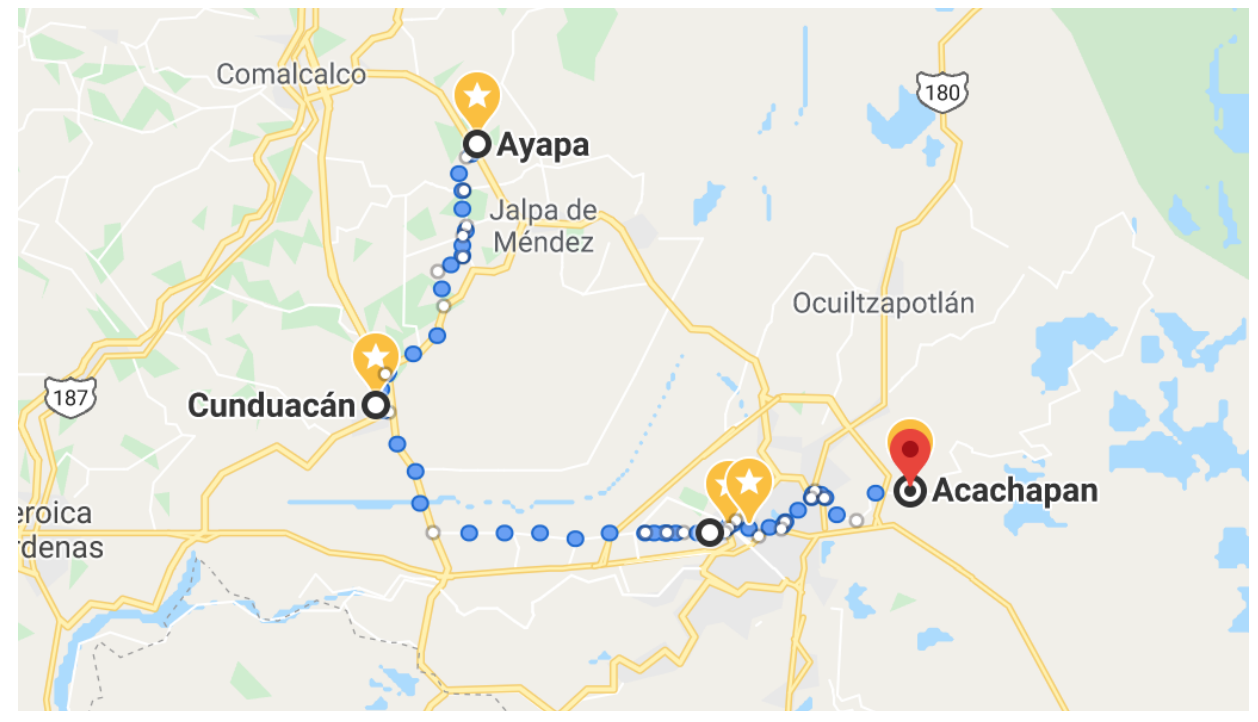

Fig. 6. Los lugares donde Marcos Juan Jaqueto conservaba bienes.

El radio comercial es interesante porque se desplegaba en las principales zonas mercantiles cacaoteras novohispanas (Tabasco, Yucatán -los pueblos zacatunes-, la región de Soconusco en Chiapas), y también se extendía por algunas zonas guatemaltecas en la fachada pacífica. Así es como dos mercaderes asentados en Guatemala, Juan Cansino y Juan de Quintanilla, le deben dos cargas y cuatro chiquipiles de cacao de Guayaquil.

Si bien su radio comercial era esencialmente americano [fachada atlántica y fachada pacífica], la realidad fue mucho más compleja y deja intuir un comercio internacional disimulado. Dos ejemplos bastarán para demostrarlo. Cuando se abrieron las petacas de Marcos Juan, y cuando se vendieron los bienes en almoneda pública en la venta de Acotalpa, aparecieron raso, damasco, tafetán, bocazín 
y sinabafa de China; telas de Ruán; corgarán de Italia; varas de Holanda; paños de Londres; tafetán de Castilla; también productos locales como coquillos (algodón) de Yucatán, mantas zoques, huipiles de Oaxaca, mantas yucatecas ${ }^{17}$, etc.

En realidad, los circuitos mercantiles de Marcos Juan eran los circuitos habituales, las tradicionales rutas que aparecen en este mapa: Manila / China; Acapulco / Veracruz; Sevilla / Europa.

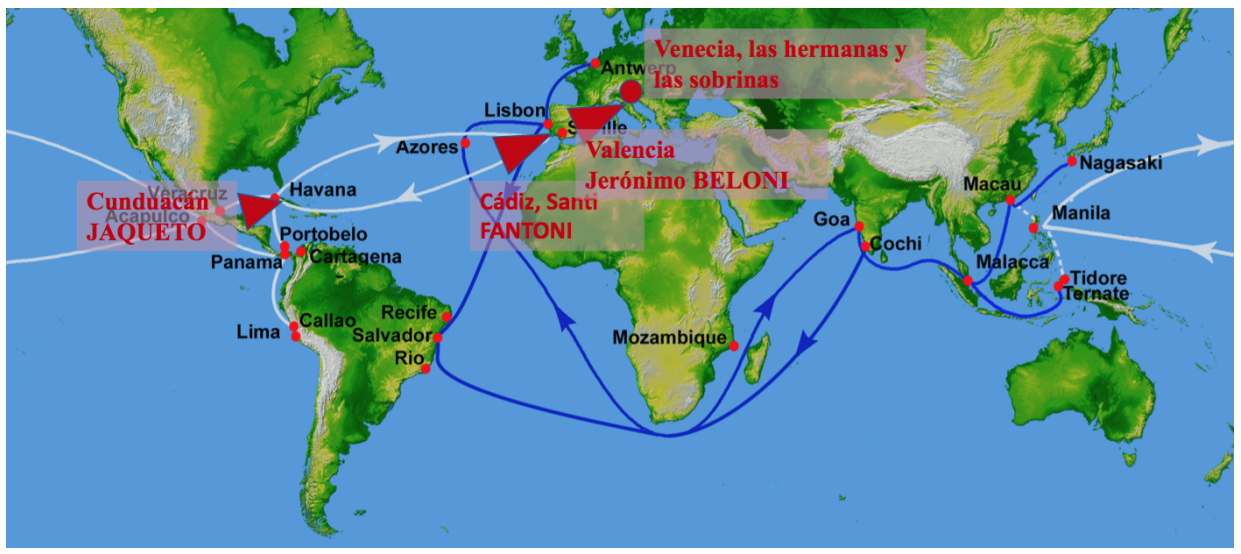

Fig. 7. El viaje del dinero de Marcos Juan Jaqueto entre China y Sevilla ${ }^{18}$.

Quisiera insistir en la ruta particular del dinero de Marcos Juan señalada arriba. En su testamento, declaró por herederas universales a sus dos hermanas vivas, Arcánguela y Silvia; quería que cada una recibiera 1.000 pesos de oro común y que Francisco de Oro (su albacea) los enviara «por cuenta y riesgo dél».

[...] los embie Francisco Doro, mi albacea registrado por cuenta y riesgo de los dichos encaminado y dirigido a la ciudad de Cádiz a Santo Fantón, regidor mercader en la dicha ciudad para que el susodicho los embie a la parte de San Pedro de Valencia para que allí se den a Jerónimo Beloni ${ }^{19}$, mercader que fue de la Nueva España [...]

17. Estas mantas de Yucatán eran de vieja tradición prehispánica (Relación históricogeograficas, p. 429 https://archive.org/details/agz9105.0002.001.umich.edu/page/III).

18. El mapa original está sacado de https://fr.wikipedia.org/wiki/Fichier:16th_century_ Portuguese_Spanish_trade_routes.png.

En blanco va representada la ruta española; en azul, la ruta portuguesa. En rojo he materializado la ruta del dinero de Marcos Juan Jaqueto.

19. No he localizado a Jerónimo Beloni, pero los Belloni son banqueros romanos en el XVIII. ¿Acaso se trata de la misma familia? 
que se entregue a las dichas mis hermanas o a sus herederos (en Venecia, San Pedro) conforme a esta cláusula porque esta es mi voluntad ${ }^{20}$.

En un primer momento, remitió el dinero a la ciudad de Cádiz, a Santo Fantón, que no era otro que Santi Fantoni, regidor perpetuo y mercader de Cádiz. Tal como nos indica Juan José Iglesias Rodríguez, los Santi Fantoni habían constituido una fructífera compañía mercantil que operó entre Nueva España, Andalucía e Italia (Iglesias Rodríguez, 2008: 63-6421). De allí, Marcos Juan pidió que el dinero se mandara a Jerónimo Belloni, que estaba en Valencia, para que éste lo entregara a sus hermanas en Venecia, mediante sus factores venecianos.

Este folio del testamento es apasionante porque arroja luz sobre una ruta del dinero perfectamente establecida, poniendo en evidencia de paso hasta qué punto la red financiera seguía siendo muy comunitaria -mercaderes toscanos, banqueros romanos-, como si en lo esencial, al fin y al cabo, siempre terminaran imponiéndose las lógicas identitarias o etnicistas, las famosas «gramáticas tribales». En todo caso, es una red que pone de manifiesto la gran banalidad de la economía-mundo y de la transferencia de numerario de una parte a la otra del orbe a finales del siglo XVI.

\section{LOS NEGOCIOS DE MARCOS JUAN}

Si analizamos muy en detalle los negocios de Marcos Juan, podemos destacar algunos puntos clave de su actividad.

\subsection{Cacao, telas: de la proyección americana a la proyección pacífica}

Marcos Juan era ante todo un mercader de cacao. Convirtiendo todas las deudas en pesos de plata, todas las cantidades de cacao en pesos, he podido llegar a la cifra global de un patrimonio de 11.500 pesos de plata más o menos.

El cálculo no ha sido sencillo a causa de la paridad de las monedas que tiende a variar de una región a otra, y de un tiempo a otro, y que me ha costado mucho establecer. Por ello he tenido que recurrir a Juan Díez Freile y a su Sumario compendioso de las cuentas de plata y oro, aunque la obra es de $1556^{22}$. Por otra parte, si bien el

20. AGI, Contratación, 502, N. 11, fol. 26v

21. Santi Fantoni fundó la compañía Santi Federighi (murió en 1604), y desarrolló su actividad como cargador a Indias. Sus hijos Francisco Fantoni y Juan Andrea Fantoni, con Luis Federighi se dedicaron al comercio con Indias.

22. Díez Freile, s. XVI, matemático que residió en México y acompañó a Cortés en su primera expedición a Yucatán como capellán. Publicó tres obras, entre ellas el primer libro de matemáticas impreso en América y titulado Sumario Compendioso de las cuentas de plata y oro. La obra de Díez consiste en unos cien folios con un conjunto de tablas dedicadas al precio 
especialista Jesús Hernández Jaimes (Hernández Jaimes, 2008: 43-79, particularmente 54 y ss) afirma que el precio del cacao se calculaba en 50 pesos en 1606, aquella cifra debió de ser más bien el precio pagado en las grandes ciudades como México, ya que en el momento de la subasta del cacao de Marcos Juan, he observado que éste se vendió al mejor postor y que en algunos lugares la carga no superó los 28 pesos de plata corriente. En el partido de Guaymango, la carga (o sea 8.000 almendras) se vendió a 28 pesos. En Veracruz, se vendió a 35 pesos. He calculado que la carga de cacao de Marcos Juan debió venderse siguiendo un promedio de 38 pesos. En efecto, la venta del cacao de Marcos Juan Jaqueto en el pueblo de Tazumete de la Barranca, partido de Guaymango, nos da algunas indicaciones de precio:

En el pueblo de Tazumete de la Barranca, jurisdicción de la villa de Tabasco, en 26 días del mes de agosto de 1603, hoy domingo día de San Bartolomé a ora de misa, congregado el pueblo en presencia de mí el escribano y testigos, por voz de Domingo Zapata, pregonero, con altas e inteligibles voces, decía, quién pone en pregón los cuatro chiquipiles de buen cacao y los 32 zontles de cacao revuelto chilacalte, dando voces quién pone en pregón, digo en precio [se autocorrige] el dicho cacao por muchos apercibimientos salió el padre Hernando Ruiz, vicario del partido de Guaymango, dijo que ponía y puso los 4 chiquipiles de buen cacao a razón de 21 pesos de oro común [...] por no haber otro mayor ponedor, el dicho pregonero en alta voz dijo ¿hay quién dé más por el dicho cacao y quién puje? Buena, buena, buena, y se llevó el cacao $[\ldots]^{23}$.

Los cuatro chiquipiles a 21 pesos de oro (que valía 556 maravedís el peso de oro) nos permite calcular el chiquipil en 2.919 maravedís; la carga (que son 3 chiquipiles), en 8.757 maravedís o 28 pesos de plata corriente, que es lo que valía en el partido de Guaymango. En 1602, a raíz de otra venta de cacao realizada por Francisco Ruiz, corredor en la Nueva Veracruz, a petición de Marcos Juan, la carga de cacao valía 35 pesos de plata corriente en la Nueva Veracruz ${ }^{24}$.

En el cuadro siguiente (Fig. 8), he intentado calcular el patrimonio global de Marcos Juan en el momento de su muerte.

de compra de varios grados de plata y oro, ensayos y cuestiones monetarias http://dbe.rah.es/ biografias/19231/juan-diez-freile.

Stanley Burdick, 2008.

23. AGI, Contratación, 502, N. 11, fol. 39r-v.

24. AGI, Contratación, 502, N. 11, fol. 158r: «[...] cacao que ha entre 39 cargas que montaron 1400 y tantos pesos [Nueva Veracruz]». 
I - Lo que le deben según las diversas cédulas que se conservaron:

- 68 pesos de oro común (a $556 \mathrm{mrs}$ ) = $37.808 \mathrm{mrs}$

- 1046 pesos (se supone de plata corriente, a $306 \mathrm{mrs}$ ) $=320.076 \mathrm{mrs}$

TOTAL $=357.884$ mrs (1.170 pesos de plata común)

II - En su testamento, las deudas que le deben (además de las cédulas ya contabilizadas):

- 328 pesos (a $306 \mathrm{mrs})=100.368 \mathrm{mrs}$

- Cacao = entre las cargas, los chiquipiles y los zontles [convirtiéndolo todo]= 259 cargas

TOTAL $=259$ cargas $(9.842$ pesos $)+328$ pesos $=10.170$ pesos

\begin{tabular}{|c|c|c|}
\hline Medidas del cacao: & & \multirow{7}{*}{$\begin{array}{l}1540=1 \text { carga }=6 \text { pesos } \\
\text { ل } 1562=1 \text { carga }=20 \text { pesos } \\
1570=1 \text { carga }=21 \text { pesos } \\
\text { ل } 1580=1 \text { carga }=28 \text { pesos } \\
1606=1 \text { carga }=50 \text { pesos } \\
\text { ע } 1621=1 \text { carga }=21 \text { pesos }\end{array}$} \\
\hline 1 zontle $=400$ almendras o granos & & \\
\hline 20 zontles $=1$ chiquipil & & \\
\hline 3 chiquipiles $=1$ carga $[8.000$ almendras $]$ & & \\
\hline 32 cargas $=1$ tonelada & & \\
\hline Por mi parte, calculo la carga en 38 pesos & & \\
\hline Precio del cacao: & & \\
\hline
\end{tabular}

El precio del cacao en Nueva España se dispara hasta el ingreso del cacao sudamericano, de Caracas, de Maraicabo y de Guayaquil (Virreinato de Perú), que provocó que para 1621 descendiera a 21 pesos la carga. TOTAL $=11.340$ pesos $=3.470 .040 \mathrm{mrs}$. En total, Marcos Juan poseía, para su negocio, casi tres millones de maravedís y medio, entre lo que le debían y las cantidades de cacao que tenía en el momento de su muerte. Si comparamos con los patrimonios evocados por Margarita Suárez (Suárez, 2001), eran cantidades medias. Marcos Juan Jaqueto no era un mercader de envergadura, sino tan solo un mercader mediano de provincia.

Además de lo que se puede contabilizar -porque se puede evaluar y convertir en pesos-, Marcos Juan poseía las mercancías siguientes: sebo (121 arrobas $=1452 \mathrm{~kg})$, «guaypiles» (huipiles), mantas zoques y yucatecas, corales, cera labrada, telas de china, paños de Holanda. También le debían «varios tostones de plata en la provincia de Chiapas». El peso de plata corriente valía 9 reales, o sea 306 maravedís. El peso de tipuzque valía 272 maravedís. Cuando no se precisaba, el peso al que se aludía era de plata corriente.

Fig. 8. Resumen de los bienes de la empresa de Marcos Juan Jaqueto. 
Primera conclusión. Con un patrimonio de casi tres millones y medio de maravedís [que totalizaron las deudas que le debían y las cantidades de cacao que tenía en el momento de su muerte], Jaqueto aparece como un mercader mediano, de provincia, que distaba mucho de competir con los mercaderes del consulado de México. Tal vez por ello su caso presente tantos aspectos interesantes... En cambio, algunos elementos son de resaltar porque indican una apertura de la compañía de Marcos Juan hacia un nuevo tipo de comercio. La presencia de cacao de la fachada pacífica en época tan temprana como los años 1600 no es un hecho anodino. El cacao, además de tener un gran valor mercantil, tenía también un valor simbólico de intercambio, una función monetaria que venía a suplir la escasez de numerario americano. De ahí que muchos encomenderos exigían que se les pagara el tributo en cacao, como fue el caso del propio Francisco de Oro, albacea de Marcos Juan. Los especialistas fijan el principio de la introducción del cacao de Guayaquil en Nueva España en torno a los años 1620 -provocando, de paso, el descenso del precio de la carga de 50 a 21 pesos (Hernández Jaimes, 2008: 50-59. Del Valle Pavón, 2011: 239-268).

Ese comercio, en teoría, había de hacerse por la fachada pacífica, de Guatemala a Acapulco, pero este comercio intercolonial quedó prohibido a instancias de los mercaderes sevillanos, quienes exigieron que se prohibiera para facilitar el control monopolístico. La consecuencia fue que se abrió un canal para el contrabando del cacao guayaquileño. Las deudas de los mercaderes de Guatemala señalan que Marcos Juan mantenía vínculos comerciales con los puertos del Pacífico, en torno al cacao principalmente, pero no exclusivamente. Ya señalé el maravilloso elenco de telas procedentes de China que entraban por el puerto de Acapulco (Bonialian, 2016: 642; Del Valle Pavón, 2015), de crea (tela fina) de Lyon, de sebo y de candelas, de azabache y de coral, que los maestres de barcos fletaban con el cacao de Marcos Juan de Tabasco a Veracruz o a San Juan de Ulúa.

Segunda conclusión. La diversificación del comercio de Marcos Juan, al ampliar su mercado tradicional con nuevos productos de lujo de alta rentabilidad, demuestra que la compañía estaba en fase de consolidación y auge. La proyección comercial americana daba paso a una proyección orientada cada vez más hacia el Pacífico, lo que supone que la capacidad financiera del veneciano iba en aumento. También debo reconocer que lo que he podido calcular, no fue más que lo que Marcos Juan comerciaba de forma "pública», legal o semi legal, a causa de su condición de extranjero.

\section{1. ¿Tráfico de la plata?}

Algo que aún se me escapa, es su tráfico ilegal de plata. Después de muchas lecturas, me llamó la atención el que Marcos Juan -cuya vida transcurría de forma austera, sin lujo ni vanagloria ninguna (no tenía casa, ni bienes raíces, vestía ropa 
muy raída o huipiles y usaba colchas viejas, cuellos usados y viejos, tantas cosas calificadas por Francisco de Torres de «inmundicias»)- tuviese tanta vajilla de plata en el momento de su muerte: picheles, jarros, saleros, calderetas, platillos, platones, un aguamanil de siete marcos y medio de plata. También me sorprendió que Francisco de Torres, apenas había llegado a Cunduacán, mandó buscar al esclavo Manuel haciendo «cabeza de proceso contra él por la fuga que ha hecho y por la evidente sospecha de la falta de plata» ${ }^{25}$. La plata era lo que verdaderamente interesaba a las autoridades, no el cacao (Del Valle Pavón, 2005: 213-240). La razón de tanta plata obrada es bastante sencilla: la vajilla no era quintada, y atesorar la plata bajo la forma de vasijas resultaba ser un medio muy sencillo de esquivar la ley obviando el pago del quinto real. El caso de Marcos Juan no debió ser excepcional porque las primeras cédulas imponiendo el famoso «derecho de vajilla» se expidieron en 1578. El impuesto que se pagaba a la Real Hacienda por «derecho de vajilla», es decir por darle a la plata un valor de utilidad, era inferior al pago del quinto real. A partir de la segunda mitad del siglo XVII, el control sobre el pago del «derecho de vajilla» se hizo más firme, pero en época de Marcos Juan, nadie lo controlaba realmente. Lo que me lleva a pensar que el veneciano debía ser hombre más rico de lo que aparentaba, si bien su testamento deja en evidencia su desapego a la riqueza y su profunda humanidad, alejada de las trabas y sujeciones del honor y de la vanagloria.

\section{UNA HUMANIDAD DIÁFANA}

\subsection{La fundación de una capilla en Tlaxcala y una sensibilidad religiosa peculiar}

La lectura del testamento de este mercader y de los diversos documentos que lo acompañan genera el sentimiento íntimo de estar ante una vida sencilla y depurada, que transcurrió lejos del mundanal ruido y de las lógicas del medrar, sin ansia de acumular ni honores, ni cargos, ni bienes. Cierto es que Marcos Juan, en principio, no tenía hijos -aunque lo más probable es que los tuviera, porque en la subasta de sus bienes, se vendió ropilla vieja de muchacho ${ }^{26}-$, y sin lugar a dudas, esta ausencia de heredero forzoso explica algunas de sus disposiciones testamentarias.

En las primeras líneas de su testamento, las invocaciones religiosas se hacen sin ampulosidad, reafirmando la fe en el misterio de la Santísima Trinidad y pidiendo a la Virgen ponga «su alma en carrera de la salvación». No voy a analizar la parte religiosa del testamento porque otros lo harían muchísimo mejor que yo. Tan

25. AGI, Contratación, 502, N. 11, fol. 31r-31v: «El teniente mandó buscar a Manuel, negro esclavo que fue de Marcos Juan, para que diese cuenta de las cosas que faltan de la petaca [...] y mandó hacer cabeza de proceso contra el dicho Manuel negro por la fuga que ha hecho y por la evidente sospecha de la falta de plata y de otras cosas que el dicho su amo dejó [...]».

26. AGI, Contratación, 502, N. 11, fol. 48r. 
solo quisiera destacar la fundación de una capilla en Tlaxcala con 500 pesos de oro común, más el remanente de sus bienes, por su alma, la de sus padres y la de su mujer difunta. Nombró por patrón y capellán al chantre Pedro Gutiérrez de Pisa -que ya no lo era de la catedral de Tlaxcala sino de la de Puebla de los Ángeles-, hombre bien conocido de la historiografía por haber sido poderdante en España, en 1584, de Juan de Cervantes, primo de Miguel de Cervantes (Moreno Hurtado, 2017: 157), y sobre todo, por haber fundado la congregación de San Pedro de México (Schwaller, 1998: 110). De esta capilla de Tlaxcala no se sabe nada fuera de lo que nos indica el testamento:

El remanente que quedare y fincare de mis bienes quiero y es mi voluntad que se junten y se den al doctor don Pedro Gutiérrez de Pisa, chantre de la ciudad de Tlaxcala, para que con los 500 pesos de oro común que tengo mandado se haga e instituya una capellanía, se junte con el dicho remanente de mis bienes y de todo, el dicho chantre haga e instituya una capellanía por mi alma y de mis padres y de mi mujer difunta y se me digan las misas que se me alcanzasen en cada semana conforme a la renta que hubiere, y nombró por patrón y capellán de la dicha capellanía al dicho doctor Pisa y por su muerte nombró patrón y capellán idóneo el que le pareciere ${ }^{27}$.

Marcos Juan nombró en su testamento, a través de las mandas, la iglesia de la villa de la Victoria de Tabasco; la cofradía de Nuestra Señora del Rosario de Tabasco; los dominicos de Yucatán; los franciscanos de Ciudad Real de Chiapas (donde estaba enterrada su mujer); y los jesuitas de Nueva Veracruz. En particular, nombró al padre Pedro de Secobia, rector de la Compañía de Veracruz, quien había ingresado en la orden en Sevilla en 1584 y conocía la lengua mexicana (Gutiérrez Casillas, 1975). El padre Secobia fue denunciado en 1603 por haber absuelto a un hereje, y no creo que aquello fuese un hecho inocente en la filiación que expresó Marcos Juan para con la Compañía. De hecho, la fe sincera y verdadera de Marcos Juan se manifestó a través de la profusión de mandas y, al mismo tiempo, a través de un absoluto desapego a la hora de ordenar sus últimas voluntades. No pide ser enterrado en un lugar determinado, ni de una forma determinada, sino en la iglesia del pueblo más cercano donde falleciere, y que se le cante una misa de requiem ese día.

\subsection{Manuel Tierra Bran, esclavo negro y cariño filial}

Marcos Juan no tenía hijos, y eso explica tal vez el amor filial que sentía por su esclavo negro Manuel Tierra Bran -procedente de la tierra de Bran, en Angola o Guinea, mandinga lo más probable-, su hombre de confianza:

27. AGI, Contratación, 502, N. 11, fol. 28. 
Ytem, declaro que yo tengo parte de mis bienes en esta provincia de Tabasco de los cuales tiene noticia y sabe donde están mi esclavo Manuel, y quiero y es mi voluntad que el dicho Manuel sea mi albacea en esta provincia ${ }^{28}$.

Marcos Juan tomó muchísimas precauciones para proteger a su esclavo, pidiendo a los albaceas repetidas veces que lo favorecieran, callando algunos bienes para que su esclavo pudiera gozar de la propiedad de éstos. La historia de este esclavo es curiosa. Al amanecer del 17 de agosto -día de la llegada de Francisco de Torres-, Manuel cogió la mula que le había dejado en el testamento Marcos Juan y huyó, según cuentan los diversos testigos, diciendo cuando se le preguntaba que se marchaba a Chiapas a verse con Francisco de Oleta ${ }^{29}$. No nos extraña que Manuel hubiera huido contemplando la codicia y brutalidad que animaba a Francisco de Torres, el cual exigió de Juan Jiménez Tovar que antes de que pasasen tres horas, acudiese con todos los bienes que el veneciano había dejado en su casa cuando allí murió. Manuel, el esclavo, se refugió en las casas de Francisco de Oleta para que éste lo defendiera y que pudiera gozar de su ahorramiento y de los bienes que su amo le había dejado. De hecho, un tal Manuel, negro, interviene en la subasta de bienes de Marcos Juan comprando sábanas, sombrero, mulas, etc. Pero ha de ser otro (o puede ser que nos escape alguna fase de la evolución del caso). En todo caso, Manuel Bran muere en 1611, en la encomienda de Francisco de Oleta, y según su testamento en Náhuatl -que por pura casualidad encontré porque un estudioso de Náhuatl lo colgó en la red a título de prácticas (Peña Vicenteño, 2009)-, poseía bastantes bienes, entre los cuales probablemente estaban algunos de aquellos que Marcos Juan había dejado sin especificar, y que Manuel recuperó con la ayuda de Francisco de Oleta:
Auto sobre Manuel negro libre difunto América, Guatemala, A1.43 (1), leg. 235, exp. 1705, 1611, Chiapas
Principalmente se inventarió cuatro mulas de carga.
Y también tres machos de Asia
Y también cinco, al parecer viejos,
Y también dos lechones
Y también otros tres lechoncillos por capar,
Y también una casa de pichones y paja

Información sobre la muerte del negro libre Manuel, ahogado en el río cerca del pueblo de San Pedro, encomienda de Francisco de Oleta. Archivo General de Centro

28. AGI, Contratación, 502, N. 11, fol. 29r-v.

29. Ibid., fol. $31 \mathrm{v}-32 \mathrm{r}:$ «[...] y aunque ha hecho [Francisco de Torres] muchas diligencias no le ha podido aver porque dicen tomó la mula buena que dejó su amo y se fue hacia la provincia de Chiapas [...] Juan Bautista de Ardalia, residente en la provincia [...] dijo que luego como falleció su amo, tomó la mula buena que dejó por sus bienes y la ensilló y preguntándole este testigo que adónde iba, dijo que a la provincia de Chiapas a verse con Francisco de Oleta [...]». 
Y también tres sillas de asentar de madera,

Y un capote viejo de paño burdo.

Y también una silla vieja jineta con sus estribos de fierro. Y también un freno de mula, Y también pareció una caja cerrada en el que se hallo lo siguiente:

Y se desarrajó por no haber hallado pa [...],

Y también unas cartas de pago sin otro. $Y$ se halló en ella un testimonio de cómo el dicho Juan era libre conforme a la clausula del testamento de dicho Mario [sic] Juan, difunto, y también una bula ${ }^{30}$.

En conclusión, Marcos Juan Jacqueto sin duda amó la tierra americana, amó a aquellos pueblos con los cuales mantuvo una relación de confianza y de respeto, como con los naturales de los pueblos zacatunes, con quien había tratado y a quien rogó que dijeran misas rezadas por su alma. A lo largo de todos sus escritos se evidencia un concepto peculiar de la vida: humildad, confraternidad más allá de las categorías sociales, exaltación del ser humano y de sus méritos propios, piedad sin gloria mundi ni vanitas.

\section{BIBLIOGRAFÍA}

Bonialian, M. (2016). La 'ropa de la China' desde Filipinas hasta Buenos Aires. Circulación, consumo y lucha corporativa, 1580-1620. Revista de Indias, 76(268).

De Vos, J. (1990). No queremos ser cristianos: historia de la resistencia de los lacandones, 1530-1695, a través de testimonios españoles e indígenas. México: Consejo Nacional para la Cultura y las Artes/Instituto Nacional Indigenista.

Del Valle Pavón, G. (2005). Los mercaderes de México y la transgresión de los límites al comercio pacifíco en Nueva España (1550-1620). Revista de Historia económica I Journal of Iberian an Latin American Economic History, La economía en tiempos del Quijote, 23.

Del Valle Pavón, G. (2011). Cacao de Guayaquil y apertura comercial. La promoción del comercio de cacao y azúcar a través del Consulado de México. En N. Böttcher et alii (coord.), Redes imperiales y negocios globales en el mundo ibérico, siglos XV-XVIII. México: Colegio de México.

Del Valle Pavón, G. (2015). El consulado de la ciudad de México en el comercio con Europa y Asia. En L. Gerardo Morales (coord.), Tornaviaje. La nao de China y el Barroco en México, 1565-1815. Madrid: Ediciones El Viso.

Fernández, S. y Fernández Allende, Y. (2016). Los aztecas y el uso del cacao como moneda. Ciudad Autónoma de Buenos Aires. Buenos Aires: Banco Central de la República Argentina.

30. El subrayado es mío. 

MERCADER VENECIANO MUERTO EN LA PROVINCIA DE TABASCO (1603)

Gutiérrez Casillas, J. (1975). Diccionario bio-bibliográfico de la Compañia de Jesús en México, t. XIV, siglo XVII, México: Editorial Tradición. http://www.fondazionein torcetta.info/pdf/biblioteca-virtuale/documento1024/diccionario14.pdf.

Heredia Herrera, A. (coord.). (1984). Catálogo de las consultas del Consejo de Indias (1605-1609). Sevilla: CSIC/Diputación.

Hernández Jaimes, J. (2008). El Fruto prohibido. El cacao de Guayaquil y el mercado novohispano, siglos XVI-XVIII. Estudios de Historia Novohispana, 39.

Herzog, T. (2014). Merchants and Citizens: On the Making and Un-making of Merchants in Early Modern Spain and Spanish America. Journal of European Economic History, 52.

Humberto Ruz, M. (2016). De la xícara a la porcelana: el peregrinar del cacao tabasqueño. En M. Humberto Ruz (coord.), Kakaw, oro aromado. México: UNAM.

Iglesias Rodríguez, J. J. (2008). Árbol de Sinople. Familia y patrimonio entre Andalucía Y Toscana en la Edad Moderna. Sevilla: Universidad de Sevilla.

Jickling, D (1982). Los vecinos de Santiago de Guatemala en 1604. Mesoamérica, Fuentes documentales y bibliográficas, 3(3).

Laguarda Trías, R. (1988). Pilotos portugueses en el río de la Plata en el siglo XVI. Coimbra: Universidad.

Mijares Ramírez, I. (1997). Escribanos y escrituras públicas en el siglo XVI. El caso de la ciudad de México. México: UNAM/Instituto de Investigaciones Históricas.

Moreno Amador, C. (2014). La población en la provincia de Tabasco durante el periodo colonial (siglos XVI-XVII) : un estudio revisionista. Naveg@mérica. Revista electrónica editada por la Asociación Española de Americanistas, 13, 2.

Moreno Hurtado, A. (2017). Los Cervantes y Cabra. Cabra.

Pease, F. y Noejovich, H. O (2000). La cuestión de la plata en los siglos XVI-XVII. Historica, 24(2).

Peña Vicenteño, J. P. (2009). Relaciones entre africanos e indígenas en Chiapas y Guatemala. Estudios de cultura maya, 34. http://www.scielo.org.mx/scielo.php?script=sci_arttex t\&pid=S0185-25742009000200006

Perez, B. (2016). Les marchands de Séville. Une société inquiète ( $X \mathrm{~V}^{\mathrm{e}}-X V I^{\mathrm{e}}$ siècles). Paris: SUP.

Poggio, E. (2011). Las composiciones de extranjeros en la Nueva España, 1595-1700. Cuadernos de Historia Moderna, 10.

Schwaller, J. F. (1998). Los miembros fundadores de la Congregación de San Pedro, México, 1577. En M. a del P. Martínez López, G. von Wobeser y J. Guillermo Muñoz Correa (coords.), Cofradias, capellanías y obras pías en la América colonial. México: UNAM.

Stanley Burdick, D. (2008). Mathematical Works Printed in the Americas 1554-1700. Baltimore: Johns Hopkins University Press.

Suárez, M. (2001). Desafíos trasatlánticos. Mercaderes, banqueros y el Estado en el Perú virreinal (1600-1700). Lima: Institut Français d'Études Andines. 